\title{
The Design and Implementaion of PTZ Control in Intelligent Video Surveillance
}

\author{
Lv Saidong and Tang Guohua \\ Institute of Security \\ Yunnan Normal University \\ Kunming,Yunnan Province,China \\ lsdong_km@sina.com
}

\author{
Xia Yaowen and Xie Jili \\ Institute of Information \\ Yunnan Normal University \\ Kunming,Yunnan Province,China \\ xywen_km@sina.com
}

\begin{abstract}
In the security monitoring system, in order to realize the multi-angle and different positions of the camera monitoring the camera monitoring, a pan tilt zoom (PTZ) module is used. This paper describes the PELCO-D protocol of PTZ and serial communication firstly. Then it achieves control the of PTZ and lens work based on Windows VC++. Finally, It discusses the main function of the system structure and coding.
\end{abstract}

Keywords-PTZ Control; Monitoring Sysetm;VC++,Codeing; Pelco-D protocol.

\section{INTRODUCTION}

In the intelligent video surveillance system, in order to expand the scope of monitoring and improve monitoring vision, camera can mount on the PTZ. Then it can control the parameters of the camera through drive PTZ camera rotation. Thus, PTZ plays a key role in the monitoring system. It is a direct reflection of the technical indicators in monitoring system.

\section{THE ANYSIS OF PTZ CONTROL MODULE}

PTZ is carrying a camera device for both horizontal and vertical direction of rotation. In order to achieve multi-angle and variable distance monitoring in the intelligence video monitor system,PTZ control module is used .The PTZ device can control the pitch and horizontal movement of the camera not only, but also can control the electronic lens aperture,focus,zoom. It is specialized monitoring equipment which is used to adjust the camera movement and location. The use of PTZ can expand its coverage and monitor the target site. Thus, it makes the intelligent video surveillance system more flexible.

PTZ control system sends control commands to the decoder through the computers serial /parallel port. Then the decoder control the corresponding relay so as to achieve the closure of the respective power switch Finally, it can achieve the focus of the camera in the vertical direction of movement of the swing in the horizontal direction as well as can achieve electronic's lens, iris and zoom, etc.

\section{THE DESIGN OF PTZ CONTROL MODULE}

PTZ control module is a software module of PTZ control motion. The PTZ cameras built-in decoder and follow standard PTZ control protocols. According to an external control signal, the program sends to commands of PTZ decoder to achieve the camera off and open, etc. The above instruction formation follows PTZ control protocol. In this paper PTZ control protocol use PELCO-D protocol[1].

\section{A. PELCO-D Protocol}

In this paper PTZ control protocol use PELCO-D protocol which is used in workers industries[2]. It is able to get the support of the decoder. Pelco is a leading global provider of well-known enterprise in the prestigious industry professional $\mathrm{R} \& \mathrm{D}$ and production video security system.PELCO-D protocol is a protocol developed by the company.Its command format is as showed TABLE I .

TABLE I. PELCO-D PROTOCOL COMMAND FORMAT

\begin{tabular}{|l|l|l|l|l|l|l|}
\hline \multicolumn{1}{|c|}{ Byte 1 } & Byte 2 & Byte 3 & Byte 4 & Byte 5 & Byte 6 & $\begin{array}{c}\text { Byte } \\
\mathbf{7}\end{array}$ \\
\hline $\begin{array}{l}\text { Synchroniz } \\
\text { ation } \\
\text { Word }\end{array}$ & $\begin{array}{l}\text { Addres } \\
\mathrm{s}\end{array}$ & Data 1 & Data 2 & Data 3 & Data 4 & $\begin{array}{l}\text { Check } \\
\text { sum }\end{array}$ \\
\hline
\end{tabular}

- In this protocol, all values are hexadecimal number.

- Synchronization byte is always FFH.

- Address code is the logical address of the camera number, address range between $00 \mathrm{H}$ to $\mathrm{FFH}$;

- Command one and command two indicate script, it performs different actions.

- Data symbols one and two represent the horizontal and vertical direction speed(00-3fH), $\mathrm{ffH}$ represent "turbo" speed.,

- The checksum=mod((byte $2+$ byte $3+$ byte $4+$ byte 5+byte 6)/100H).

\section{B. Data Encoding}

In this paper, Data encoding should normally follow the principles[3]:

- Instruction data width should be as short as possible.

- Data encoding which is adjacent or similar operation of the corresponding should maintain continuous. For example, the upwardly corresponding to the operation instruction data is 01000000 , then the downward corresponding to the operation instruction data is 01000001

Through the serial port or parallel port to send commands, each instruction corresponding to specific coding differences according to the conventions of the decoder. It is best to design the program to run the state under the load of each instruction encoding in common PTZ 
control system. In this way, the program to connect to the new decoder, simply change the data in the instruction encoding files on it. Set in the program "control code editor" function block, you can edit control in a running application code, click the "confirm" button, the new encoding settings are stored in the data file. When the configuration file is not found, the program uses the default instruction set as showed in Figure 1.

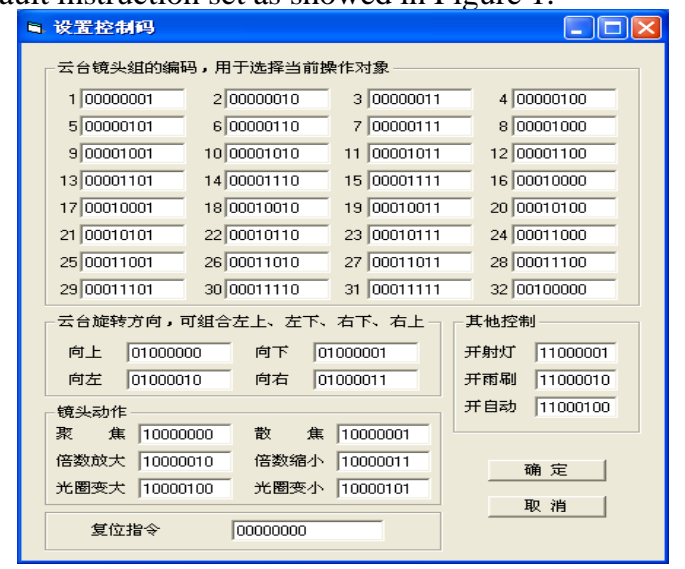

Figure 1. Edit dialog box and the default instruction control code.

\section{THE IMPLEMENTION OF PTZ CONTROL MODULE}

\section{A. PTZ Control Protocol Process}

PTZ control module mainly realize PTZ control on,down,left,right direction,control and vertical monitor the level of monitoring,wide-angle monitoring.PTZ control protocol process as shown in Figure 2.

\section{B. Software Design of PTZ Control System}

Decoder plays a central role in PTZ camera control system.PTZ camera control system is mainly to solve the problem is to encode each operation, it can resolve and control relays disconnect closed through decoders receive instruction. The decoder is used for a device to communicate with the computer; it encapsulates the preparation of the program of the underlying hardware. Therefore it only need to use the decoder develop protocol through issue a directive to the decoder via RS232 or Rs485 serial interface.

\section{The Implementation of PTZ System}

The program uses the programming environment is Microsoft Visual C++ 6.0, the main use of the technology is the serial programming. Use Microsoft Visual $\mathrm{C}++6.0$ to write a function to send commands to the serial port. Because the PTZ of the upper,lower,left,right,gather focus,aperture,windshield wipers to write the function of the process is similar. Therefore, in order to control PTZ down function description of the process of programming, mainly divided into initialize port and control PTZ movement function[4][5]

1) Initialize port information, the main set as follows:

- $\quad$ Serial port baud rate is set to 9600 .
- The data buffer size can be set to 512 bytes.

- The port number of Serial communication port number set 1

- The SetPortOpen function is used to open a serial port.

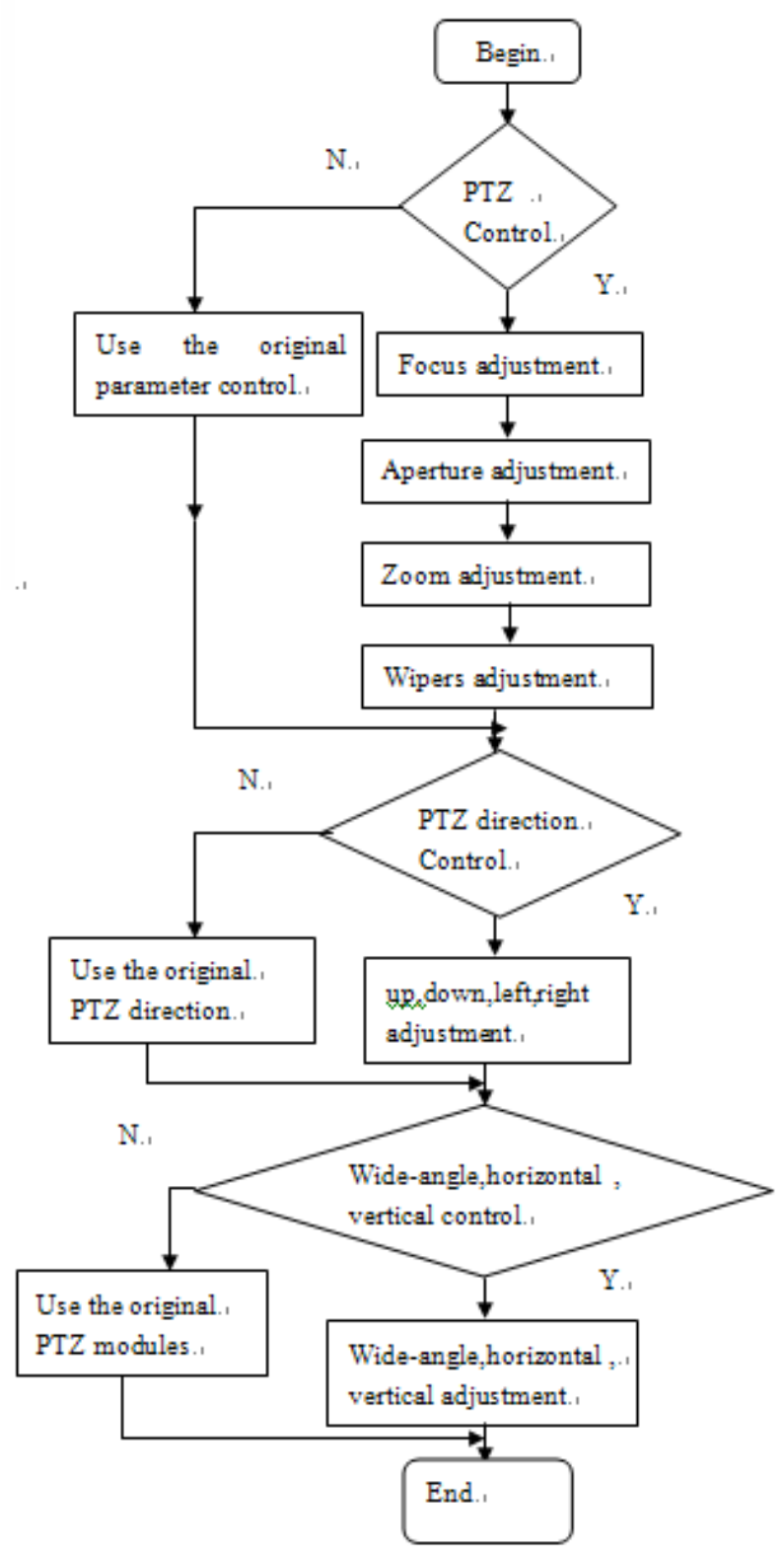

Figure 2. The process of PTZ control protocol

2)The function of control PTZ moving down

The running process of control PTZ moving down function is as follows[6]:

- Set PTZ movement control instructions corresponding coding instruction data.

- Create a data format for the serial port to send SAFEARRAY.

- The instruction data memory is stored in the SAFEARRAY. 
- $\quad$ The applicable serial ports send SAFEARRAY.

\section{3)System interface}

The interfaces of running program are showed in as Figure 3 and Figure 4.

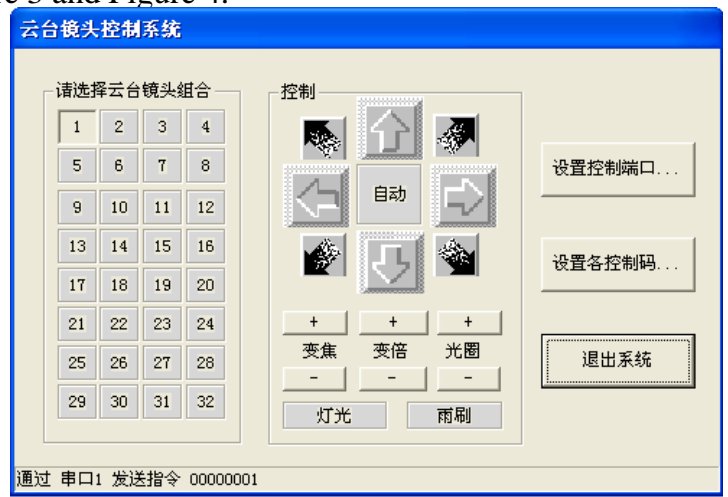

Figure 3. The main interface of System

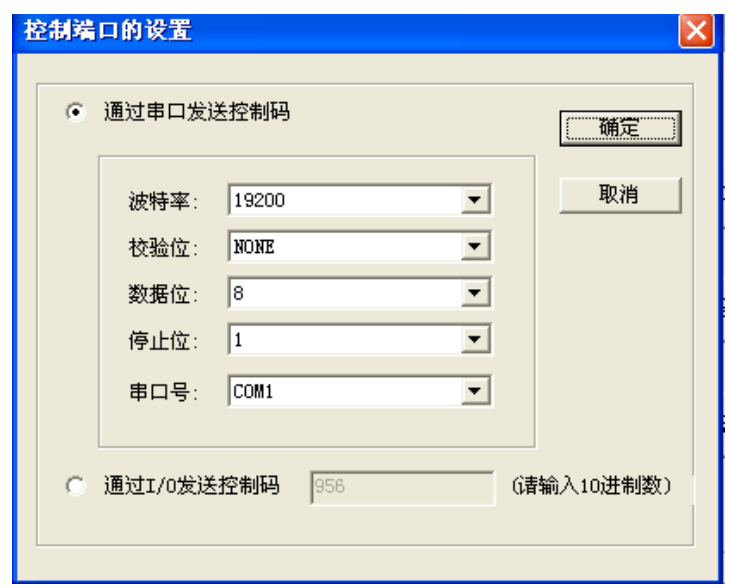

Figure 4. The interface of Portal setting

\section{CONCLUSIONS}

In this paper mainly discusses the related concepts of PTZ control and the implementation process of PTZ control protocol PELCO-D. Then implement a prototype system based on Microsoft VC++ 6.0.The system has been applied to our campus video surveillance system for six months. The system is stable, reliable and has a certain application value. PTZ control and face detection combined to achieve intelligent PTZ control module in the future.

\section{ACKNOWLEDGMENT}

This work is supported by the National NSF of China (No.60903131), the Natural Science Fund (NSF) of Yunnan Province (No.2004F0017Q, 2005F0022Q, 2009ZC0052M).

\section{REFERENCES}

[1] Shen Qijie,Ling jie.The design and implemention of plug-in framework based on C\#[J] .

[2] Huang Xiaojian. Multimedia technology[M] Beijing Unviersity of Posts and Telecommunications on Press,2000:76-83

[3] Zhang Meiqi,Hu Guowen. The design and programming of highperformance PTZ control[J],Security Technology ,2008,8.

[4] Yang Feng,Gui Wei hua,Chen Feng.Serial communication programming method in WIN32 environment based on $\mathrm{VC}++$ 6.0[j].Computer Technology and Automation,2004,23(2),70-73.

[5] Li Yan,Li Weiming,Li He,Visual C++ project development through the Record[M].Tsing University Press,2008:210-245.

[6] Zhang Honglin. Proficient Visual C++ serial communication technology and engineering practice[M].People's Posts and Telecommunications Press 2008:367-371. 